\title{
QUALITATIVE APPROACHES IN STATISTICS EDUCATION RESEARCH
}

\author{
SUE GORDON (Guest Editor) \\ The University of Sydney \\ Sue.Gordon@sydney.edu.au \\ ANNA REID (Guest Editor) \\ The University of Sydney \\ Anna.Reid@sydney.edu.au \\ PETER PETOCZ (Editor) \\ Macquarie University \\ Peter.Petocz@mq.edu.au
}

\section{INTRODUCTION}

We are pleased to introduce the SERJ special edition on qualitative approaches to statistics education research. The eight papers that follow were selected from those submitted by authors following a call for papers in the May 2009 edition: They illuminate various aspects of qualitative approaches to research in statistics education, set in a variety of different teaching contexts and disciplines, four different countries, and two different languages. As editors of this edition, we also add our own diversity - Sue is a statistics educator focusing on psychology and other service areas, Anna is a musician and music educator, and Peter is an applied statistician and statistics educator. We all have experience with qualitative (as well as quantitative) approaches to pedagogical research.

One of our aims in putting together this special edition has been to highlight the range of qualitative approaches and methodologies that are available for research in statistics education. Although statistics education research traditionally favours quantitative methodology, an investigation of the archive of previous issues shows that SERJ has often published research studies utilising qualitative approaches. One of the particular features of this special edition is that each of the authors has included specific discussion of the qualitative methodology that they have utilised and its contribution to their research approach.

The papers in this current issue, together with those published during the previous decade, demonstrate the important role that qualitative research plays in the investigation of the various aspects of statistics pedagogy, complementary to the contributions based on quantitative approaches.

\section{THE STATISTICAL APPROACH}

Tukey's description of statistics as "numerical detective work" (1977, p. 1) points out the fact that statistics is a quantitative discipline, focused on numerical data, set essentially in the positivist framework. The quantitative nature of statistics is often inherited by statistics education research, which is mostly carried out by statisticians and statistics educators. The gold standard in experimental research practice is the randomised

Statistics Education Research Journal, 9(2), 2-6, http://www.stat.auckland.ac.nz/serj (C) International Association for Statistical Education (IASE/ISI), November, 2010 
controlled trial, derived from areas such as medical research, and this standard is often held up as the aim for pedagogic studies - and sometimes even promoted by legislation (Shelley, Yore, \& Hand, 2009; and see also Hake, 2010). Yet statistics as a discipline has some key qualitative aspects: amongst them, the decision of what to measure and how to measure it, the selection and wording of questions for a survey, and indeed the very notion of categorisation, as Bowker and Starr (2000) explore in the context of medical and racial classifications.

It is interesting to read that in earlier times statistics included the notion of qualitative description and investigation, though this is not part of current ideas about the discipline. De Bruyn's (2004) essay on the emergent science of statistics explores its links with literary representations of the time. In the $18^{\text {th }}$ and early $19^{\text {th }}$ centuries, statistics referred to a description of the state or nation, drawing heavily on qualitative analyses: It was described by an early writer, Zimmermann in 1787, as "the branch of political knowledge which has for its object the actual and relative power of the several modern States, the power arising from their natural advantages, the industry and civilisation of their inhabitants, and the wisdom of their government" (quoted in De Bruyn, p. 112). Questions about a country's productivity, wealth, and well-being were addressed using analyses based on observed characteristics, such as its progress in agriculture or its accomplishments in architecture, without necessarily utilising any measurements. De Bruyn writes that "statistics and graphs ... bear significant affinities with some of the major literary forms in the period, in particular, the novel and the topographical or georgic-descriptive poem" (p. 107).

This historical link between the quantitative and the qualitative does not seem to be currently utilised by statistics education. This suggests an approach that could capture the interest of some of our more literary students: Ask them to write about the statistical aspects of one of Henry Fielding's novels, for instance, or to prepare a presentation on the topic of chorography!

\section{QUALITATIVE APPROACHES}

Statisticians and statistics educators know about and use a variety of quantitative statistical methods, but some of them are less aware of the diversity of qualitative methodologies. In this special edition, we display a variety of such methods, based on various epistemological approaches. Each of these (and others) needs to come to grips with the issues of validity and reliability — or rather, their qualitative counterparts - and to demonstrate the legitimacy of their approaches and conclusions.

Kreber (2002) describes a useful framework consisting of three categories for engagement with qualitative (or quantitative) pedagogical research. Her first category contains studies of an observational and experiential character that describe statistical problems in the classroom or lecture theatre and provide practical teaching advice on their solution. The underlying epistemology here is one of observation, assuming that the problems described are common and the proposed solutions will be seen as useful by practitioners. Kreber's second category is identified by a more systematic approach of scholarly reflection - studies that hold their practice up to reflective scrutiny, aimed at pedagogical change that improves the quality of learning and teaching. The epistemology has shifted to an evidence-based approach. The third category is represented by those pedagogical studies that utilise a designed research effort. Such designed studies can be carried out using a wide range of qualitative (or quantitative) research methodologies, for instance, ethnography, action research, phenomenography, or critical theory. 
Each of these methodologies implies a particular epistemological approach which views participants, artifacts, and researchers in different relationships. For instance, the observational approach suggests that the researcher has the capability of making "correct" judgments about a situation based on their own professional knowledge. The reflective approach seeks to verify the "truth" of a situation through an investigation of multiple artifacts and reliance on the researcher's judgment. The designed-study approach starts with the construction of a specific question and develops an appropriate method to investigate it. As in all research approaches, qualitative or quantitative, the initial questions are derived from researcher curiosity. However, from that point the nature of the problem demands particular approaches to its investigation.

A common requirement of all approaches is to demonstrate the rigorous nature of the research by answering the following questions: Why would you (or others) trust the findings of this particular research project? How does this particular research orientation address the issues of reliability and validity? Can the results of this project, involving people in one situation, be transferred to another? Each of these questions of rigour has the potential to generate thorny philosophical, as well as practical, debate amongst researchers working in different fields. For instance, researchers using phenomenology focus on the rich description of a person's life-world (Schutz, 2002). This might seem to be at odds with the desire to make the results transferable beyond the specific research situation. In this situation, it may be more suitable to think of the extension beyond the individual as inference.

De Bruyn (2004) also discusses this point in relation to early statistics: Statistical tables comprise isolated facts about, say, the state of a country, and the reader has to draw overall conclusions based on the trustworthiness of the descriptions presented and on probable reasoning. He writes "One way to ratify a heterogeneous collection of particulars as reliable, as 'factual,' and to underwrite their coherence is to emphasize the trustworthiness of the observer.... Projecting oneself as an impartial observer/reporter is one way, then, to solicit the reader's assent to the veracity of one's facts and to affirm that they add up to a systematic understanding of things" (pp. 118-119). Quantitative approaches address this problem in two ways: Firstly, a numerical representation is used to counter any perception of bias (though, of course, this does not solve the problem); secondly, the numbers are gathered using the probabilistic notion of randomness (which results in an "unbiased sample" from the population, though, again, this does not necessarily solve the original problem). Qualitative approaches have to achieve the same aim in other ways!

Guba and Lincoln (1989) proposed that the notion of trustworthiness as a qualitative equivalent of rigour demands that four criteria are met: The research must be credible, transferable, dependable, and confirmable. They claim that these criteria lend authenticity to the research. From a statistician's perspective these may seem reasonable: However, each of these criteria can be contested. The important issue for qualitative researchers is to recognise the positions that they hold, write about them so that others can make their own judgments about the research from their own perspectives, and provide evidence for claims made regarding the research. Beyond this, it seems common in the statistics education research area to strengthen legitimacy by the use of statistical language-terms such as control, significant, power and unbiased - used in a non-statistical sense.

\section{THE PAPERS}

Our special edition of SERJ begins with a paper by Randall Groth, who positions the dilemma about the legitimacy of qualitative research by reviewing questions that he 
identifies as having "re-surfaced" in recent, influential, policy documents in the USA. Groth examines the discourse and philosophical orientations surrounding five key questions implicitly or explicitly raised by the documents. These questions are the following: Is qualitative research scientific? Is qualitative research rigorous? Is qualitative research generalisable? Is qualitative research useful beyond exploratory studies? Is qualitative research objective? In addressing these questions, he brings to the foreground the debate about the characteristics and value of qualitative research to inform and advance the field of statistics education.

Pav Kalinowski, Jerry Lai, Fiona Fidler, and Geoff Cumming add insights about the contribution and pitfalls of both qualitative and quantitative approaches in the context of their research in statistical cognition. Their broad motivation is statistical reform in psychology. In their account of four studies, these researchers show how qualitative methods can offer broad, rich description, reveal new directions, help capture subtleties, and even correct misinterpretations of quantitative results. They argue that issues about subjectivity and bias are not confined to the qualitative domain and that principles underpinning rigour in qualitative studies, such as recognising and acknowledging bias, should also be expected of quantitative research.

A change of setting is introduced by Michelle McGinn, who presents a qualitative case study of statistical practice in a university-based statistical consulting centre. She looks at "statistics in action" through interactions among consultants and clients in the centre and identifies key themes of statistics learning and practice related to different aspects: types of clients and consulting interactions, disciplinary and statistical expertise, and the role of material objects and representations. McGinn concludes that a statistical consulting centre provides opportunities for learning by both consultants and clients and contributes positively to teaching and research for a university.

All the authors of our special issue highlight the fact that qualitative research is embedded in the social setting and makes explicit the connections to this setting. Stephanie Casey applies this strength of qualitative research to studying three teachers in practice at secondary school. Her investigation of the teachers' subject-matter knowledge draws on a diversity of data sources and focuses on a core aspect of knowledge for teaching statistical association - the correlation coefficient. The findings provide rich descriptions of the knowledge base for teaching about correlation that are grounded in the classroom context as well as advancing the theoretical construct of teacher knowledge.

Jane Watson and Erica Nathan continue in the school context in their extensive project aiming to capture teachers' pedagogical content knowledge for teaching statistics to middle-school students. Unexpectedly, through a qualitative interview approach with the participating teachers, some surprising insights about the teachers' different experiences in teaching statistics as opposed to mathematics came to light. It is this subsidiary yet significant theme that is the focus of their paper. They found that qualitative analysis of issues that arose in the interview material spoke to the researchers "with greater force" than if responses had been elicited in a pre-given direction.

The diversity of methodological approaches and philosophical orientations supporting qualitative research is well illustrated by our final three papers. Alain Bihan-Poudec uses a phenomenological approach to examine a philosophical problem. His paper is written in French, and accompanied by an extended summary in English. His critique of a "pedagogy of proximity" - teaching closer to the students' lifeworld - reveals surprising outcomes. The arguments puts forward in this paper lead us to think beyond the seemingly obvious in finding solutions to advancing students' understanding of statistics.

Drawing on her personal history, Jennifer Green uses a naturalistic enquiry to explore the pedagogic experiences of university teaching assistants (she was one of them). The 
descriptions capture the teaching assistants' perceptions about teaching introductory statistics and include data on the relationships influencing the teaching assistants. The study highlights the essence of the qualitative approach in revealing what people know.

Our final paper is bound to stimulate, or perhaps provoke, discussion and response. Agnes Petocz and Glenn Newbery argue that "conceptual analysis" is the primary qualitative approach - equally applicable whether the further study will be carried out using quantitative or qualitative methodology, or any combination of them. At the same time, these authors challenge some widely-accepted ideas about the nature of the qualitative-quantitative distinction. One such is the notion that the researcher can make an a priori choice whether to utilise a qualitative or quantitative approach: The authors argue that the selection method must be a logical consequence of the nature of the problem being investigated and the variables selected for study.

\section{TOWARDS NEW KNOWLEDGE}

Several authors in this special edition base their papers around the idea of pursuing aspects of their studies that were surprising or novel and that only came to light on the basis of a qualitative approach. From the editors' point of view, as researchers familiar with qualitative approaches, this was not unexpected. One of the advantages of qualitative methodologies is that they are often involved in the discovery of new knowledge, found by looking around the edges of the research data or making connections between seemingly unrelated aspects. The notion of "new" knowledge is an interesting one. As our colleagues with serendipitous findings demonstrate, newness comes from being aware of variation and that variation is seen to emerge from the data. The papers illustrate that knowledge can be uncovered using qualitative approaches in situations that are often studied using quantitative approaches. Could this be the most important contribution of qualitative approaches to statistics education research?

\section{REFERENCES}

Bowker, G., \& Starr, S. (2000). Sorting things out: Classification and its consequences. Cambridge MA: The MIT Press.

De Bruyn, F. (2004). From Georgic poetry to statistics and graphs. The Yale Journal of Criticism, 17, 107-139.

Guba, E., \& Lincoln, Y. (1989). Fourth generation evaluation. Newbury Park, CA: Sage.

Hake, R. (2010). Seventeen statements by Gold-Standard skeptics.

[Online: http://tinyurl.com/3az7tvu]

Kreber, C. (2002). Teaching excellence, teaching expertise, and the scholarship of teaching. Innovative Higher Education, 27(1), 5-23.

Schutz, A. (2002). The phenomenology of the social world. In C. Calhoun, J. Gertis, J. Moody, S. Pfaff, \& I. Virk (Eds.), Contemporary sociological theory (pp. 32-41). Blackwood Publishing: Oxford.

Shelley, M., Yore, L., \& Hand, B. (2009). Education research meets the "gold standard": Evaluation, research methods, and statistics after No Child Left Behind. In M. Shelley, L. Yore, \& B. Hand (Eds.), Quality research in literacy and science education: International perspectives and gold standards (pp. 3-15). Dordrecht, The Netherlands: Springer.

Tukey, J. (1977). Exploratory data analysis. Reading, MA: Addison-Wesley. 